\title{
Quality improvement activity for improving pain management in acute extremity injuries in the emergency department
}

\author{
Hyung Lan Chang ${ }^{1}$, Jin Hee Jung ${ }^{2,3}$, Young Ho Kwak', Do Kyun Kim', \\ Jin Hee Lee ${ }^{4}$, Jae Yun Jung ${ }^{1}$, Hyuksool Kwon ${ }^{4}$, So Hyun Paek', \\ Joong Wan Park', Jonghwan Shin²

\begin{abstract}
'Department of Emergency Medicines, Seoul National University Hospital, Seoul, Korea ${ }^{2}$ Department of Emergency Medicines, SMG-SNU Boramae Medical Center, Seoul, Korea
\end{abstract} \\ ${ }^{3}$ Department of Preventive Medicine, Kangwon National University School of Medicine, Chuncheon, Korea \\ ${ }^{4}$ Department of Emergency Medicine, Seoul National University Bundang Hospital, Seongnam, Korea
}

Objective The aim of this study was to investigate the effectiveness of a quality improvement activity for pain management in patients with extremity injury in the emergency department (ED).

Methods This was a retrospective interventional study. The patient group consisted of those at least 19 years of age who visited the ED and were diagnosed with International Classification of Diseases codes S40-S99 (extremity injuries). The quality improvement activity consisted of three measures: a survey regarding activities, education, and the triage nurse's pain assessment, including change of pain documentation on electronic medical records. The intervention was conducted from January to April in 2014 and outcome was compared between May and August in 2013 and 2014. The primary outcome was the rate of analgesic prescription, and the secondary outcome was the time to analgesic prescription.

Results A total of 1,739 patients were included, and $20.3 \%$ of 867 patients in the pre-intervention period, and $28.8 \%$ of 872 patients in the post-intervention period received analgesics $(\mathrm{P}<$ 0.001). The prescription rate of analgesics for moderate-to-severe injuries was 36.4\% in 2013 and $44.5 \%$ in $2014(\mathrm{P}=0.026)$. The time to analgesics prescription was 116.6 minutes (standard deviation 225.6) in 2013 and 64 minutes (standard deviation 75.5) in 2014 for all extremity injuries. The pain scoring increased from $1.4 \%$ to $51.6 \%$.

Conclusion ED-based quality improvement activities including education and change of pain score documentation can improve the rate of analgesic prescription and time to prescription for patients with extremity injury in the ED.

Keywords Pain management; Emergency service, hospital; Quality improvement

\author{
Received: 3 October 2017 \\ Revised: 25 December 2017 \\ Accepted: 25 December 2017 \\ Correspondence to: Jin Hee Jung \\ Department of Emergency Medicines, \\ SMG-SNU Boramae Medical Center, \\ 20 Boramae-ro 5-gil, Dongjak-gu, \\ Seoul 07061, Korea \\ E-mail: 77saja@hanmail.net
}

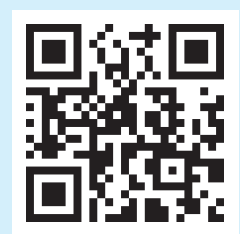

How to cite this article:

Chang $\mathrm{HL}$, Jung JH, Kwak YH, Kim DK, Lee JH, Jung JY, Kwon H, Paek SH, Park JW, Shin J. Quality improvement activity for improving pain management in acute extremity injuries in the emergency department. Clin Exp Emerg Med 2018;5(1):51-59.
This is an Open Access article distributed under the terms of the Creative Commons Attribution Non-Commercial License (http:// creativecommons.org/licenses/by-nc/4.0/). 


Capsule
$\begin{aligned} & \text { What is already known } \\ & \text { Although it is essential to actively manage the patient's pain in the emergency department, prior quality improvement } \\ & \text { activities targeting emergency department pain management in Korea have not been sufficient. }\end{aligned}$
$\begin{aligned} & \text { What is new in the current study } \\ & \text { Quality improvement activities based on medical staff education and pain documentation on in the electronic medical } \\ & \text { record improved pain management of acute extremity injury patients. }\end{aligned}$

\section{INTRODUCTION}

Pain is one of the most common symptoms of patients presenting to the emergency department (ED). Nevertheless, the assessment of pain severity was not required in most Korean EDs until the introduction of the Korean Triage Acuity Scale by the amendment of the Enforcement Regulations of the Emergency Medical Care Act of 2016. There are few studies on pain control for patients who presented to the ED, and there has been little research on pain control pain for ED trauma patients. ${ }^{1,2}$ Trauma patients have reported low satisfaction with their pain management. ${ }^{3}$ In several studies, the authors reported that only $21 \%$ to $68 \%$ of patients with moderate acute pain received analgesics, and 50\% to $74 \%$ of patients still had moderate pain at discharge. ${ }^{4,5}$ Inappropriate pain control after trauma can result in poor treatment results and can slow wound healing and recovery. Additionally, rapid and effective pain control can increase patient satisfaction with care. ${ }^{6,7}$

Because of the low awareness of the medical staff for pain assessment and congestion in the emergency room, pain management was not adequately addressed in many emergency rooms in Korea before the introduction of the Korean Triage Acuity Scale. Aggressive intervention activities including various methods have been proposed, but these are difficult for many EDs that lack resources.

The purpose of this study was to investigate the effectiveness of simple quality improvement (QI) activities for early pain management of patients with extremity injury in the ED.

\section{METHODS}

\section{Study setting}

This was a retrospective pre-post intervention study. The study hospital was an 800-bed hospital with approximately 55,000 ED visits annually. The 40-bed ED has an average of 12 physicians (7 residents and 5 emergency medicine-boarded staff) and 34 nurses, and there was no difference in personnel placement over the 2-year study period. Prior to the study period, the nurses did not record pain scores routinely in the $E D$, and pain scores were recorded based on individual discretion. This study was approved by the institutional review board of the Boramae Medical Center (26-2016-35) and waived the requirement for informed consent.

\section{Study population}

All patients aged 19 years and older who were admitted with an extremity injury were included during the study periods. The diagnosis of extremity injury was defined according to the International Classification of Diseases 10th revision (ICD-10) codes (S40S99) in ED electronic medical records (EMRs). Period I was from May to August, 2013, and period II was the same months in 2014. We excluded drunk patients; transfer patients; patients who came to the hospital for bites, burns, and foreign bodies; and patients with damage to other parts of the body (head and trunk). We excluded cases of infection such as cellulitis after previous recent trauma.

\section{Data collection and definition of variables}

Data were collected via a review of EMRs. Demographic data (age and sex), clinical information (date, time of arrival at ED, chief complaint, time to prescription of analgesics, and type of pain medication), pain score documentation on the nursing chart of EMRs, and ED discharge diagnosis (ICD-10 code) were surveyed. The severity of injury was categorized into mild and moderate-tosevere injuries according to ICD-10 codes. Because Sx0.x and Sx1. $x$ in the ICD-10 codes correspond to superficial injury and open wound of any extremity area, respectively, the numbers 0 and 1 in the second digit of the ICD-10 code were classified as a mild injury. Other injuries, including fractures; dislocations; injuries of nerves, blood vessels, and muscles; and multiple or unspecified injuries were classified as moderate-to-severe injuries. For example, 'fracture of the upper arm' (S42.3) was classified as a moderate-to-severe injury and 'contusion of forearm' (S50.1) was classified as a mild injury. Pain was assessed using a numeric rating scale and written as a number, 0 to 10, on the nursing charts in the EMRs. 


\section{Ql activity}

The Ol activity was started in January 2014 and had three components: a survey about the perception of ED pain management by nurses and physicians, education for $\mathrm{Ol}$ activity, and changes in pain scoring practice by triage nurses through revisions to EMRs (Fig. 1). The survey was performed in February 2014, and the contents included basic information on the participant, awareness of ED pain management, reasons for inappropriate pain management, reasons for difficulty in pain assessment, individual pain assessment methods, and methods of improving pain management. After analyzing the causes of oligoanalgesia in the $E D$, pain management education and changes in the protocol for pain documentation were suggested. For education on the Ol activity, two emergency grand round meetings were used to explain the need for and methods of $\mathrm{Ql}$ activity before the intervention period (January and April 2014) for ED physicians and nurses. Each staff group discussed the $\mathrm{Ol}$ activity approximately once per month in their regular meetings for four months (January to April 2014). Pain assessment was recommended at the triage step and was to be recorded by the triage nurse. The default value for pain score was changed from 'no' to 'yes' to increase pain scoring on EMRs in February 2014.

\section{Outcome measures}

The primary outcome was the prescription rate of pain medications in patients with limb trauma who visited the emergency room. The secondary outcome was the time to prescription of the first analgesic in the ED.

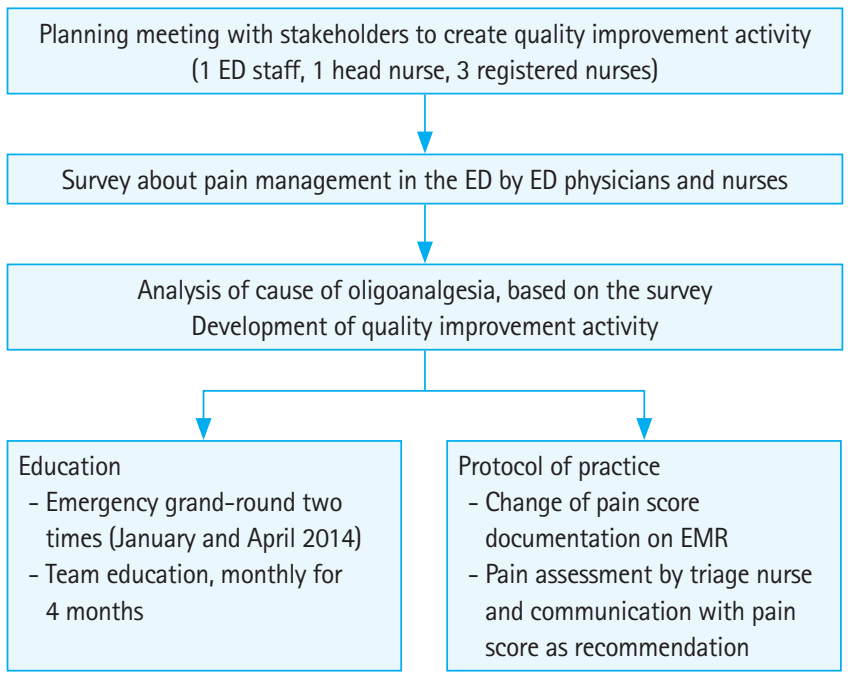

Fig. 1. Flow of quality improvement activity. ED, emergency department; EMR, electronic medical record.

\section{Data analysis}

Continuous variables are presented as means with standard deviations or $95 \%$ confidence intervals, and categorical variables are presented as frequencies and percentages (\%). The chi-square test and Fisher exact test were used to compare categorical data. Student's t-test was used to compare continuous variables. The time to prescription of analgesics by each month was calculated as means and standard errors. Multiple logistic regression analysis was used to analyze factors associated with analgesics prescription. P-values $<0.05$ were considered statistically significant. IBM SPSS Statistics ver. 22.0 (IBM Corp., Armonk, NY, USA) was used.

\section{RESULTS}

\section{Demographics of participants}

In total, 2,490 patients with extremity injuries (ICD-10 codes S40S99) visited the ED during the study period, and 1,739 patients were included after applying the exclusion criteria (Fig. 2). There was no difference in mean age and age distribution between the two groups, but sex was different (Table 1). In both groups, the most common location of injuries was the wrist and hand ( $550-$ S59), followed by the ankle/foot and knee/lower leg. The locations and the types of injuries were not significantly different between the two groups ( $P=0.428$ and 0.310 , respectively). The rate of admission was higher in period I than in period II $(P=0.006)$. The

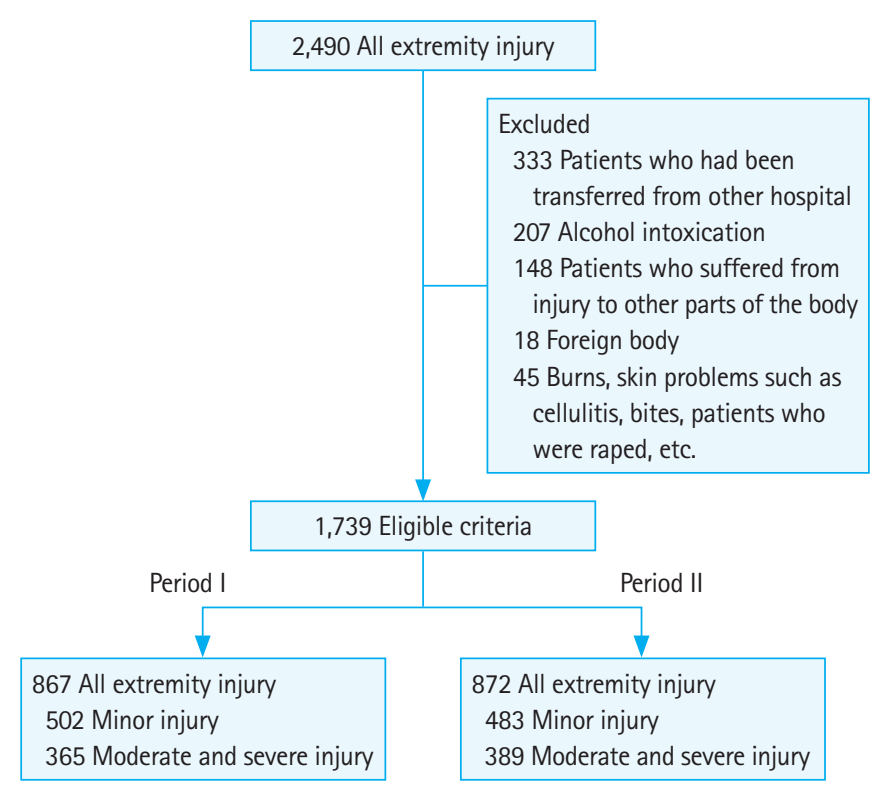

Fig. 2. Study participants. Injury severity was categorized according to the International Classification of Disease 10th revision code. Superficial and open wounds were defined as minor injuries, and other injuries except superficial and open wounds were defined as moderate-to-severe injuries. 
Table 1. Demographics of participants

\begin{tabular}{lccc}
\hline Characteristics & $\begin{array}{c}\text { Period I } \\
(n=867)\end{array}$ & $\begin{array}{c}\text { Period II } \\
(n=872)\end{array}$ & P-value \\
\hline Age (yr) & $44.6 \pm 18.3$ & $45.2 \pm 18.5$ & 0.519 \\
Age group (yr) & & & 0.706 \\
19-39 & $414(47.8)$ & $396(45.4)$ & \\
40-59 & $262(30.2)$ & $284(32.6)$ & \\
60-79 & $153(17.6)$ & $151(17.3)$ & \\
80-99 & $38(4.4)$ & $41(4.7)$ & \\
Sex, male & $443(51.1)$ & $392(45)$ & 0.011 \\
Time of emergency department visit & & & $0.267^{\text {a) }}$ \\
$\quad$ 08:00-17:59 & $375(43.3)$ & $401(46)$ & \\
00:00-07:59/18:00-23:59 & $492(56.7)$ & $471(54)$ & \\
Hospitalized & $116(13.4)$ & $80(9.2)$ & $0.006^{\text {a) }}$ \\
Fracture & $215(24.8)$ & $202(23.2)$ & 0.432 \\
Location of injury & & & 0.428 \\
$\quad$ Shoulder and upper arm & $63(7.3)$ & $61(7.0)$ & \\
Elbow and forearm & $88(10.1)$ & $100(11.5)$ & \\
Wrist and hand & $321(37.0)$ & $297(34.1)$ & \\
Hip and thigh & $56(6.5)$ & $59(6.8)$ & \\
Knee and lower leg & $144(16.6)$ & $129(14.8)$ & \\
Ankle and foot & $195(22.5)$ & $226(25.9)$ & \\
Injury severity & & & 0.310 \\
Minor injury (superficial or open wound) & $502(57.9)$ & $483(55.4)$ & \\
Moderate-to-severe injury) & $365(42.1)$ & $389(44.6)$ & \\
Pain scoring on chart & $14(1.6)$ & $450(51.6)$ & $<0.001$ \\
Prescription of analgesics & $176(20.3)$ & $251(28.8)$ & $<0.001$ \\
\hline
\end{tabular}

Values are presented as mean \pm standard deviation or number $(\%)$.

${ }^{\text {a) }}$ Fisher exact test. ${ }^{\text {b) }}$ racture, dislocation, injury of nerve, vessel and muscle, crushing or amputation. times of ED visits and the rates of fractures did not differ significantly between the two groups $(P=0.267$ and 0.432 , respectively). The rate of pain scoring documentation on EMR nursing charts increased significantly, from $1.4 \%$ to $51.6 \%(P<0.001)$.

\section{Survey results of the perception of pain management by physicians and nurses}

Of the ED physicians and nurses, 93.5\% responded to the survey. The responders were 11 emergency physicians (residents and boardcertified staff) and 32 emergency room registered nurses. Of them, $72.1 \%$ were women, and the age group of 20 to 29 years was the most common (58.1\%). Table 2 shows the survey results. The respondents answered in the middle level for appropriateness of pain management and difficulty of pain assessment. The cause of inappropriate pain management was thought to be due mainly to ED crowding, not low recognition and lack of pain assessment. Education experience in pain assessment was reported by $46.5 \%$. Several methods for early pain management in the ED were suggested: communication between healthcare providers for pain management and the use of standing orders for pain control.

\section{Rate of analgesic prescription and time to analgesic prescription in periods I and II}

Of the 1,739 patients, 427 (24.6\%) were prescribed analgesics during entire combined period. The analgesic prescription was

Table 2. Results of survey about perception of emergency physicians and nurses regarding pain management in the emergency department

\begin{tabular}{|c|c|}
\hline Questions regarding the emergency department setting & Value \\
\hline Appropriateness of pain management, Likert scale ${ }^{a)}$ & $3.3(3.1-3.5)$ \\
\hline How difficult was pain assessment? Likert scale ${ }^{a}$ & $2.9(2.6-3.1)$ \\
\hline Education experience of pain assessment, yes & $20(46.5)$ \\
\hline \multicolumn{2}{|l|}{ Cause of inappropriate pain management, Likert scale ${ }^{a)}$} \\
\hline Low recognition of the importance of pain management & $2.5(2.2-2.8)$ \\
\hline Lack of pain assessment and communication about patients' pain & $2.6(2.3-2.8)$ \\
\hline Delay in pain medication preparation & $3.2(2.8-3.6)$ \\
\hline Emergency department crowding & $4.2(4.0-4.5)$ \\
\hline \multicolumn{2}{|l|}{ Minimum score for analgesics administration } \\
\hline 3 Or more & $2(4.7)$ \\
\hline 4 Or more & $18(41.9)$ \\
\hline 5 Or more & $12(27.9)$ \\
\hline 6 Or more & $2(4.7)$ \\
\hline 7 Or more & $9(20.8)$ \\
\hline \multicolumn{2}{|c|}{ Method for early pain management in our emergency department (multiple choice) } \\
\hline Communication between healthcare provider for pain management & $20(46.5)$ \\
\hline Use of pain score when communicating between healthcare providers & $15(34.9)$ \\
\hline Early pain medication prescription by triage nurse & $9(20.9)$ \\
\hline Use of standing order for pain control & $18(41.9)$ \\
\hline
\end{tabular}

Values are presented as mean (95\% confidence interval) or number (\%).

a) $1-5$ points: 1 point means never agree, 3 points means neutral, and 5 points means absolutely agree. 
Table 3. Comparison of the prescription rate of analgesics and time to prescription between periods I and II

\begin{tabular}{|c|c|c|c|c|c|c|}
\hline & \multicolumn{3}{|c|}{ Prescription rate of analgesics } & \multicolumn{3}{|c|}{ Time to prescription ( $\mathrm{min}$ ) } \\
\hline & Period I & Period II & P-value & Period I & Period II & P-value \\
\hline Patients who receive analgesics & $176 / 867(20.3)$ & $251 / 872(28.8)$ & $<0.001$ & $116.6 \pm 225.6$ & $64.0 \pm 75.5$ & $<0.001$ \\
\hline \multicolumn{7}{|l|}{ Age group (yr) } \\
\hline $19-39$ & 47/414 (11.4) & 79/396 (19.9) & 0.001 & $111.8 \pm 132.8$ & $61.4 \pm 73.6$ & 0.020 \\
\hline $40-59$ & $67 / 262(25.6)$ & $88 / 284(31.0)$ & 0.184 & $99.0 \pm 217.8$ & $62.6 \pm 80.4$ & 0.196 \\
\hline $60-79$ & $46 / 153(30.1)$ & $59 / 151(39.1)$ & 0.117 & $104.6 \pm 191.0$ & $59.6 \pm 46.3$ & 0.125 \\
\hline 80-99 & $16 / 38(42.1)$ & 25/41 (61.0) & 0.117 & $239.2 \pm 451.3$ & $87.5 \pm 111.3$ & 0.206 \\
\hline \multicolumn{7}{|l|}{ Sex } \\
\hline Male & $105 / 443(23.7)$ & $113 / 392(28.8)$ & 0.098 & $119.0 \pm 242.3$ & $70.2 \pm 91.0$ & 0.033 \\
\hline Female & $71 / 424(16.7)$ & $138 / 480(28.8)$ & $<0.001$ & $113.1 \pm 242.3$ & $58.9 \pm 59.7$ & 0.067 \\
\hline \multicolumn{7}{|l|}{ Time of emergency department visit } \\
\hline $08: 00-17: 59$ & $84 / 375(22.4)$ & 136/401 (33.9) & $<0.001$ & $130.2 \pm 287.7$ & $62.0 \pm 70.0$ & 0.035 \\
\hline 00:00-07:59/18:00-23:59 & 92/492 (18.7) & $115 / 471(24.4)$ & 0.034 & $104.2 \pm 148.6$ & $66.4 \pm 81.6$ & 0.030 \\
\hline \multicolumn{7}{|l|}{ Hospitalized } \\
\hline Admission & $57 / 116(49.1)$ & $53 / 80(66.3)$ & 0.020 & $182.8 \pm 358.0$ & $83.6 \pm 104.0$ & 0.049 \\
\hline Discharge/transfer/AMA & 119/751 (15.8) & 198/792 (25.0) & $<0.001$ & $84.9 \pm 107.4$ & $58.7 \pm 65.1$ & 0.017 \\
\hline \multicolumn{7}{|l|}{ Fracture } \\
\hline Fracture & $105 / 215$ (48.8) & $113 / 202(55.9)$ & 0.170 & $137.2 \pm 275.1$ & $68.7 \pm 84.6$ & 0.016 \\
\hline No fracture & $71 / 652(10.9)$ & 138/670 (20.6) & $<0.001$ & $86.2 \pm 115.1$ & $60.2 \pm 67.1$ & 0.082 \\
\hline \multicolumn{7}{|l|}{ Injury severity } \\
\hline Minor & 43/502 (8.6) & 78/483 (16.1) & $<0.001$ & $79.0 \pm 108.0$ & $66.3 \pm 81.1$ & 0.505 \\
\hline Moderate-to-severe & 133/365 (36.4) & $173 / 389(44.5)$ & 0.026 & $128.8 \pm 251.3$ & $63.0 \pm 73.0$ & 0.004 \\
\hline \multicolumn{7}{|l|}{ Location of injury } \\
\hline Shoulder and upper arm & $26 / 63(41.3)$ & $33 / 61(54.1)$ & 0.208 & $55.6 \pm 65.6$ & $55.2 \pm 47.7$ & 0.981 \\
\hline Elbow and forearm & $34 / 88(38.6)$ & $43 / 100(43.0)$ & 0.556 & $51.6 \pm 45.6$ & $60.3 \pm 56.1$ & 0.454 \\
\hline Wrist and hand & $31 / 321(9.7)$ & 44/297 (14.8) & 0.064 & $99.8 \pm 133.1$ & $65.9 \pm 83.7$ & 0.216 \\
\hline Hip and thigh & $28 / 56(50.0)$ & 33/59 (55.9) & 0.577 & $276.6 \pm 478.1$ & $83.2 \pm 93.5$ & 0.044 \\
\hline Knee and lower leg & 29/144 (20.1) & 45/129 (34.9) & 0.007 & $119.3 \pm 141.7$ & $48.8 \pm 40.3$ & 0.014 \\
\hline Ankle and foot & 28/195 (14.4) & $53 / 226(23.5)$ & 0.019 & $108.2 \pm 135.9$ & $71.9 \pm 101.7$ & 0.221 \\
\hline
\end{tabular}

Values are presented as number (\%) or mean \pm standard deviation. AMA, against medical advice.
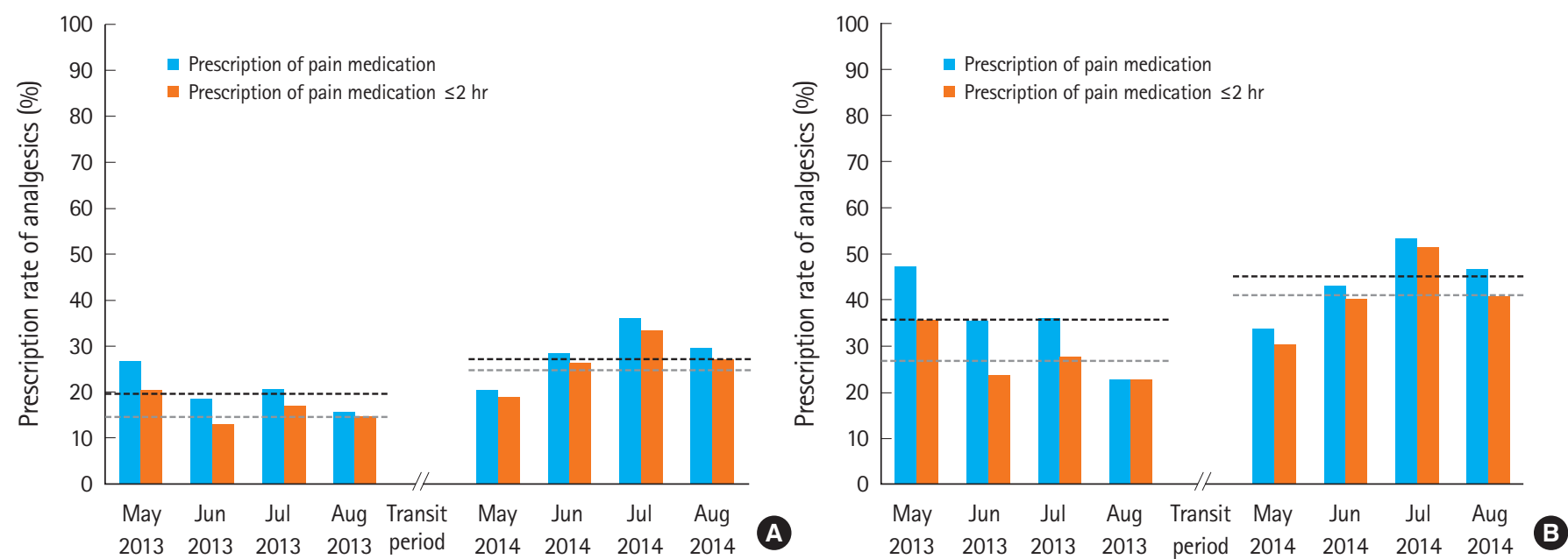

Fig. 3. The prescription rate was significantly increased after intervention. (A) Black dotted lines are the average prescription rate: $20.3 \%$ in 2013 and $28.8 \%$ in $2014(\mathrm{P}<0.001)$. Gray dotted lines are the average prescription rate within 2 hours: 16.3\% in 2013 and $26.6 \%$ in 2014 ( $<<0.001)$. (B) The prescription rate increased among patients with moderate and severe injuries. Black dotted lines are the average prescription rate: $36.4 \%$ in 2013 and $44.5 \%$ in $2014(P=0.026)$. Gray dotted lines are the average prescription rate within 2 hours: 27.9\% in 2013 and 41.1\% in 2014 $(P<0.001)$. 
significantly higher in period II than period I (difference 8.5\%, $P<0.001$ ) (Table 3). According to injury severity, the analgesic prescription rate for mild injuries increased significantly by $7.5 \%$ and that for moderate-to-severe injuries increased by $8.1 \%$ after intervention (Table 3). The difference was even more pronounced in patients who received analgesics within 2 hours (difference $10.3 \%$ and $13.2 \%$ in all participants and moderate-to-severe inju$\mathrm{ry}$, respectively) (Fig. 3). The mean time to prescription decreased by 52.6 minutes among all patients with extremity injuries, and the time to prescription decreased by 65.8 minutes among patients with moderate and severe injuries (Table 3 and Fig. 4). The analgesic prescription rate after intervention was significantly increased in the following groups: age 19 to 39 years, female patients,

Table 4. Predictors of prescription of analgesics among patients with extremity injury in the emergency department

\begin{tabular}{lccc}
\hline & \multirow{2}{*}{$\begin{array}{l}\text { Odds } \\
\text { Variable }\end{array}$} & \multicolumn{2}{c}{$95 \%$ Confidence interval } \\
\cline { 4 - 4 } & ratio & Lower & Upper \\
\hline Age & 1.010 & 1.003 & 1.018 \\
Sex, male & 1.524 & 1.179 & 1.970 \\
Quality improvement activity, post-inter- & 1.934 & 1.504 & 2.488 \\
$\quad$ vention period & & & \\
Injury severity, moderate and severe injury & 2.220 & 1.661 & 2.968 \\
Isolated extremity fracture & 3.163 & 2.359 & 4.239 \\
Admission & 2.604 & 1.756 & 3.863 \\
Location of injury & & & \\
$\quad$ Shoulder and upper arm & & & \\
Elbow and forearm & 2.884 & 1.816 & 4.579 \\
$\quad$ Wrist and hand & 2.110 & 1.396 & 3.188 \\
Hip and thigh & 0.596 & 0.415 & 0.856 \\
Knee and lower leg & 1.312 & 0.760 & 2.266 \\
Ankle and foot & 1.302 & 0.882 & 1.920 \\
\hline
\end{tabular}

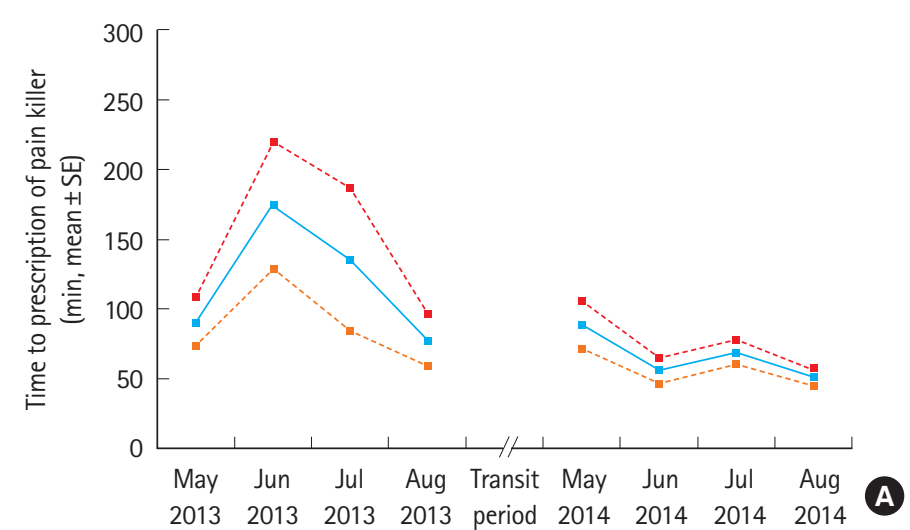

no fracture, knee/lower leg injuries, and ankle/foot injuries; the prescription rate was also increased in patients regardless of the time of day of presentation to the ED, regardless of whether the patient was admitted or discharged, and regardless of the injury severity. The time to prescription was significantly decreased in the following groups: age 19 to 39 years, male patients, fractures, moderate-to-severe injury, hip/thigh injuries, knee/lower leg injuries; the time was also decreased regardless of the time of day of presentation to the ED, and regardless of whether the patient was admitted or discharged.

\section{Predictors of prescription of analgesics by physician}

Table 4 shows the multivariable analyses for the prescription of analgesics. Using variables with $\mathrm{P}$-values $>0.2$, age, sex, $\mathrm{Ql}$ activity, injury severity, any extremity fracture, patients who were hospitalized, and location of the injury were analyzed as significant predictors for analgesic prescription. The rate of analgesic prescription was higher in period II than in period I (odds ratio, 1.934; 95\% confidence interval, 1.504 to 2.488 ).

\section{DISCUSSION}

In this study, an ED-based Ql activity for pain management in acute extremity injuries was effective in increasing the rate of analgesic prescriptions. The time to prescription was also shortened significantly after the simple intervention.

To increase the prescription rate of analgesics, it is important to evaluate the pain; this is the first stage of pain management. Unfortunately, the prevalence of pain evaluation in the nursing records before the intervention was low, less than 1.4\%. Thus, the purpose of the study was to increase the rate of pain scoring doc-

Fig. 4. Time from registration to prescription of analgesics before and after quality improvement activity. (A) The time to prescription decreased from 111.6 to 64.0 minutes among all patients with extremity injuries who received analgesics $(\mathrm{P}<0.001)$. (B) The time to prescription decreased from 128.8 to 63.0 minutes among patients with moderate and severe injuries $(P<0.001)$. SE, standard error. 
umentation in EMRs. After the simple intervention, the pain scoring increased, up to $50 \%$, and the time to prescription decreased by more than 50 minutes. Interestingly, the prescription rate of analgesics was more significantly increased in patients with minor injuries, and the time to prescription was significantly improved in patients with moderate-to-severe injuries, after the intervention. Previous studies have reported that younger and chronic pain patients received more opioids and other drug prescriptions at the time of discharge, and fewer analgesic medications were prescribed in compromised patients and elderly patients. ${ }^{8}$ The rates of prescription of pain medication were higher in elderly patients, in men, in moderate and severe injuries, in fractures, in upper extremity long-bone injuries, and in subsequently hospitalized patients in this study. In addition, patients in the intervention group were twice as likely to be prescribed pain medication compared to patients in the non-intervention group. These results are readily understandable in comparison with the results of a recent multicenter study on pain management according to the type of fracture, which suggested that analgesics are prescribed at a higher rate because long-bone fractures are more common in elderly patients. ${ }^{9}$

Pain management is of interest in many areas of medicine, and many studies are underway to develop guidelines for pain control, to assess the adequacy of analgesics, and to manage them in particular patient groups..$^{10-13}$ Problems with oligoanalgesia in the ED have been reported in previous studies. Berben et al. reported that the average number of patients complaining of pain in the ED was $88.5 \%$, and that two-thirds of the trauma patients also complained of moderate-to-severe pain. ${ }^{2}$ Pain relief at discharge was effective in approximately $37 \%$ of patients, $46 \%$ reported no change, and $17 \%$ reported increased pain. Paul et al. determined the efficacy of pain scores in ED trauma patients; $53 \%$ of patients were treated with analgesics, and 60\% of them had pain scores. ${ }^{4}$ Their study showed that through pain assessments, pain medications were administered to people with severe pain. ${ }^{4}$ In a prospective blinded observational study, pain assessment and control was even worse than in prior retrospective studies. ${ }^{14}$ Additionally, opioids are often recommended for moderate-to-severe pain, and the rate of administration is high; our study also showed a high rate of opioid use in fractures and patients with moderate-to-severe pain. ${ }^{15}$ In a study analyzing the use of analgesics in extremity or clavicle fractures, $64 \%$ of all patients received analgesics and $42 \%$ received narcotic analgesics. Moreover, $73 \%$ of patients with moderate or severe pain received an analgesic and 54\% received narcotic analgesics. ${ }^{16}$ In this study, the prescription rate of analgesics for the fracture group was not increased to the same extent as the increased documentation of pain score. There are many reasons why the prescription rate might not have risen sufficiently: First, some ED staff could not attend the Ol education and group meeting due to work schedules, and the education was not an essential program for all staff. Second, any feedback or monitoring of $\mathrm{Ql}$ activity was performed during the intervention. Because pain documentation by the triage nurse was not obligatory during the $\mathrm{Ql}$ activity, the rate of pain score documentation was only approximately 50\%. Considering that the prescription rate of pain medication in the group with a pain recording was $34.9 \%$, which is higher than that for all subjects, the prescription rate is expected to rise as the pain rate increases.

Improved pain management in this study was achieved by a survey about pain management in the ED, ED staff education, and changing the practice of the triage nurse's documentation of pain scores in the EMRs. According to the results of the survey, the perception of ED pain management by physicians and nurses was inconsistent with the low analgesic prescription rate during the study period. Although the healthcare providers evaluated a middle level of appropriateness, the prescription rate of analgesics was only approximately $20 \%$ before the $\mathrm{Ol}$ activity. This mismatch in the results may reflect a low perception for the need of pain control. For this reason, the ED-based Ol activity included education about pain management for healthcare providers: the current status of pain control in the ED, the importance of pain management, and methods of pain assessment. An important component of the $\mathrm{Ol}$ activity was to change the default value from 'no' to 'yes' for pain scoring. Because the emergency room operates 24 hours/day, 365 days/year, and includes a staff of various occupations, it is important to use objective pain scores to share the patient's condition among healthcare providers. The benefits of pain assessment have been demonstrated in several studies. ${ }^{17,18}$ Studies have shown significant pain reduction at the hospital level after pain medication was prescribed through a pre-hospital pain assessment. A study also showed an increase in prescription rates for pain medications in post-operative pain patients after a $\mathrm{Ol}$ activity for post-operative pain control. ${ }^{17,18}$ The incidence of pain assessment, reevaluation, and pain score recording was found to be generally associated with reduced pain time, as in our study. ${ }^{19,20}$ The reduction in analgesics administration time through these pain medication improvement activities has also been shown in pediatric studies. ${ }^{21}$

This study has several limitations. First, because it was a retrospective single-center study, it could not reflect the variable groups of patients among different EDs. However, the study included more than 1,700 isolated patients with extremity injury in the ED, and the characteristics of participants did not differ between periods. Second, the threshold for pain control was not defined as the pa- 
tients' subjective pain score, but a researcher's decision based on injury severity using ICD-10 codes. Because only $1.4 \%$ before the intervention and approximately half of the patients after the intervention had pain scoring by the triage nurse, it was difficult to compare appropriate pain control by the patients' pain during the two periods. For this reason, we used the ICD-10 diagnosis to compare the two groups. The distribution of diagnoses was similar in both periods. Third, the time to prescription was used instead of the time to analgesic injection. It was not possible to determine accurate analgesic injection times. The time to injection is affected by various factors, such as the transfer time for the medication, time to intravenous access, and ED crowding. We focused on the time to prescription by a doctor after the $\mathrm{Ql}$ activity. The mean time to a prescription was approximately 60 minutes, which could be considered a long time for early pain control. The time to prescription was defined as the time from ED registration to prescription of an analgesic by a doctor. The time from ED registration to triage was approximately 10 to 20 minutes, and the time from triage to doctor examination was 20 to 30 minutes in this hospital. Therefore, it can be assumed that the time from examination to prescription was improved to within 30 minutes. Fourth, this study did not exert adequate effort, such as creating posters, inviting personal feedback, or requiring an essential education program, to ensure that all ED staff received the intervention. The authors intentionally wanted to achieve appropriate pain management with a simple intervention. Therefore, modifying the EMR pain score recording method and employing a simple intervention activity of monthly meetings is meaningful and can lead to pain relief and decreased times to prescription. Considering that the analgesics prescription rate was not sufficiently improved in the present study, an increased number of and more diverse intervention activities are required to meet a future goal of increased analgesic prescriptions.

In summary, ED-based $\mathrm{Ol}$ activities, including a change in pain score documentation in the EMR, can improve the rate of analgesic prescription and time to prescription for patients with extremity injuries in the ED.

\section{CONFLICT OF INTEREST}

No potential conflict of interest relevant to this article was reported.

\section{REFERENCES}

1. Pierik JG, IJzerman MJ, Gaakeer MI, et al. Pain management in the emergency chain: the use and effectiveness of pain man- agement in patients with acute musculoskeletal pain. Pain Med 2015;16:970-84.

2. Berben $S A$, Meijs TH, van Dongen RT, et al. Pain prevalence and pain relief in trauma patients in the accident \& emergency department. Injury 2008;39:578-85.

3. Carroll KC, Atkins PJ, Herold GR, et al. Pain assessment and management in critically ill postoperative and trauma patients: a multisite study. Am J Crit Care 1999;8:105-17.

4. Silka PA, Roth MM, Moreno G, Merrill L, Geiderman JM. Pain scores improve analgesic administration patterns for trauma patients in the emergency department. Acad Emerg Med 2004; 11:264-70.

5. Todd $\mathrm{KH}$, Ducharme J, Choiniere $M$, et al. Pain in the emergency department: results of the pain and emergency medicine initiative (PEMI) multicenter study. J Pain 2007:8:460-6.

6. Hedderich $R$, Ness TJ. Analgesia for trauma and burns. Crit Care Clin 1999;15:167-84.

7. Brooks JM, Titler MG, Ardery G, Herr K. Effect of evidence-based acute pain management practices on inpatient costs. Health Serv Res 2009;44:245-63.

8. Heins JK, Heins A, Grammas M, Costello M, Huang K, Mishra S. Disparities in analgesia and opioid prescribing practices for patients with musculoskeletal pain in the emergency department. J Emerg Nurs 2006;32:219-24.

9. Siddiqui A, Belland L, Rivera-Reyes $L$, et al. A multicenter evaluation of emergency department pain care across different types of fractures. Pain Med 2017;18:41-48.

10. Simone CB 2nd, Vapiwala N, Hampshire MK, Metz JM. Cancer patient attitudes toward analgesic usage and pain intervention. Clin J Pain 2012;28:157-62.

11. Liu Z, Lian Z, Zhou W, et al. National survey on prevalence of cancer pain. Chin Med Sci J 2001;16:175-8.

12. Ko A, Harada MY, Smith EJ, et al. Pain assessment and control in the injured elderly. Am Surg 2016;82:867-71.

13. Samuel N, Steiner IP, Shavit I. Prehospital pain management of injured children: a systematic review of current evidence. Am J Emerg Med 2015;33:451-4.

14. Ducharme J, Barber C. A prospective blinded study on emergency pain assessment and therapy. J Emerg Med 1995;13: 571-5.

15. Schneider C, Yale SH, Larson M. Principles of pain management. Clin Med Res 2003;1:337-40.

16. Brown JC, Klein $E$, Lewis $C W$ Johnston $B D$, Cummings P. Emergency department analgesia for fracture pain. Ann Emerg Med 2003:42:197-205.

17. Gerhardt RT, Reeves PT, Kotwal RS, Mabry RL, Robinson JB, Butler F. Analysis of prehospital documentation of injury-re- 
lated pain assessment and analgesic administration on the contemporary battlefield. Prehosp Emerg Care 2016;20:3744.

18. Stanek JJ, Renslow MA, Kalliainen LK. The effect of an educational program on opioid prescription patterns in hand surgery: a quality improvement program. J Hand Surg Am 2015; 40:341-6.

19. Hatherley C, Jennings N, Cross R. Time to analgesia and pain score documentation best practice standards for the emer- gency department: a literature review. Australas Emerg Nurs J 2016;19:26-36.

20. Steinberg PL, Nangia AK, Curtis K. A standardized pain management protocol improves timeliness of analgesia among emergency department patients with renal colic. Qual Manag Health Care 2011;20:30-6.

21. Iyer SB, Schubert CJ, Schoettker PJ, Reeves SD. Use of qualityimprovement methods to improve timeliness of analgesic delivery. Pediatrics 2011;127:e219-25. 